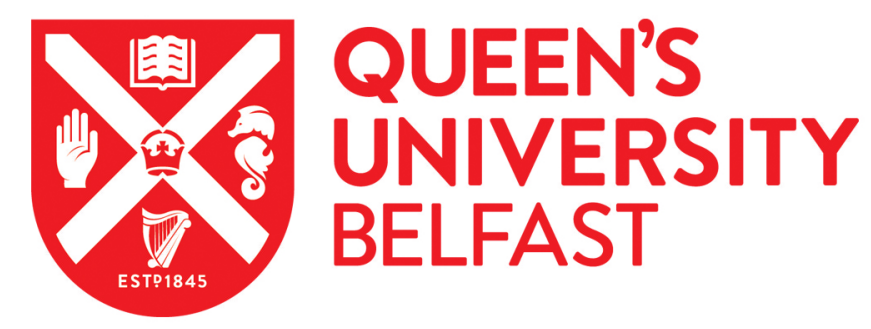

\title{
A psychosocial intervention for stroke survivors and carers: 12 month outcomes of a randomized controlled trial
}

Minshall, C., Castle, D. J., Thompson, D. R., Pascoe, M., Cameron, J., Apputhurai, P., Knowles, S. R., Jenkins, Z., \& Ski, C. (2020). A psychosocial intervention for stroke survivors and carers: 12 month outcomes of a randomized controlled trial. Topics in stroke rehabilitation, 27(8), 563-576.

https://doi.org/10.1080/10749357.2020.1738677

Published in:

Topics in stroke rehabilitation

Document Version:

Peer reviewed version

Queen's University Belfast - Research Portal:

Link to publication record in Queen's University Belfast Research Portal

Publisher rights

Copyright 2020 Taylor \& Francis. This work is made available online in accordance with the publisher's policies. Please refer to any applicable terms of use of the publisher.

\section{General rights}

Copyright for the publications made accessible via the Queen's University Belfast Research Portal is retained by the author(s) and / or other copyright owners and it is a condition of accessing these publications that users recognise and abide by the legal requirements associated with these rights.

Take down policy

The Research Portal is Queen's institutional repository that provides access to Queen's research output. Every effort has been made to ensure that content in the Research Portal does not infringe any person's rights, or applicable UK laws. If you discover content in the Research Portal that you believe breaches copyright or violates any law, please contact openaccess@qub.ac.uk. 
1 A psychosocial intervention for stroke survivors and carers: 12 month outcomes of a

2

20 randomized controlled trial

Cover title: Psychosocial intervention for stroke survivors and carers

Catherine Minshalla,b, David J. Castle ${ }^{\mathrm{b}, \mathrm{c}}$, David R. Thompson ${ }^{\mathrm{c}, \mathrm{d}}$, Michaela Pascoe ${ }^{\mathrm{e}}$, Jan

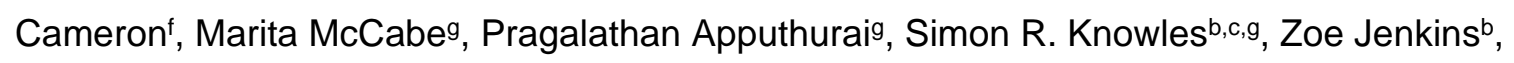

Chantal F. Skic,d

${ }^{a}$ Centre for Mental Health, University of Melbourne, Melbourne, Australia; ${ }^{b}$ Mental

Health Service, St. Vincent's Hospital, Melbourne, Australia; ' Department of Psychiatry,

University of Melbourne, Melbourne, Australia; ' School of Nursing and Midwifery, Queen's

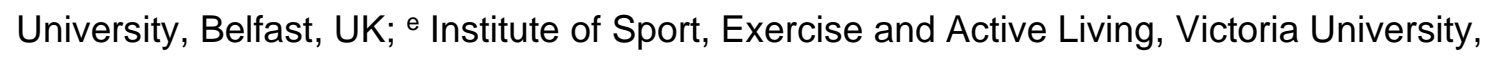

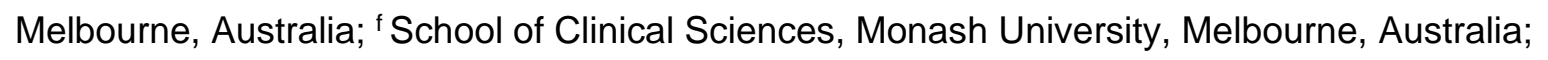

g Faculty of Health Sciences, Swinburne University, Melbourne, Australia

*Corresponding author: School of Nursing and Midwifery, Queen's University Belfast, Medical Biology Centre, 97 Lisburn Road, Belfast BT9 7BL, UK. Email: David.Thompson@qub.ac.uk

Word count: 3226

Clinical Trial Registration: ACTRN12615001046594. Registered 7 October 2015 
5

6

9

A psychosocial intervention for stroke survivors and carers: 12 month outcomes of a

\section{randomized controlled trial}

Cover title: Psychosocial intervention for stroke survivors and carers

Key Words: stroke, survivors, carers, psychosocial, RCT, quality of life

\section{Tables and Figures}

Figure 1. Flow of participants through the trial

Table 1. Content and structure of the intervention

Table 2. Primary and secondary outcome measures and time points

Table 3. Baseline characteristics of stroke survivors in the SCOHP and usual care groups

Table 4. Baseline characteristics of carers in the SCOHP and usual care groups

Table 5. The Cronbach $\alpha$ for each outcome (measure) at the four time points

Table 6. The effect of the intervention (SCOHP) between groups and over time 


\section{ABSTRACT}

Background and Purpose: Stroke can have a devastating impact on the mental and physical health of stroke survivors and their carers. We aimed to evaluate the effectiveness of a novel psychosocial intervention designed to improve health outcomes in both groups.

Methods: We conducted a randomized controlled trial of a personalized psychosocial intervention (8 one hour weekly sessions plus 1 booster) compared to usual care for adult stroke survivors and carers. Participants recruited from hospital services and community referrals completed questionnaires at baseline, 3, 6 and 12 months. Primary outcomes were quality of life and self-efficacy; secondary outcomes were depressive and anxiety symptoms, coping, illness perception, work and social adjustment, carer strain and carer satisfaction. Mixed-effect model repeated measures analysis between groups and across time was conducted.

Results: Of the 173 participants recruited (89 stroke survivors; 84 carers), a total of 137 participants -73 stroke survivors (intervention $n=42$; usual care $n=31$ ) and 64 carers (intervention $n=35$; usual care $n=29$ ) - underwent analysis up to 12 months. No statistically significant differences were found in the primary outcomes between groups over time, though a significant improvement in carer satisfaction was found at 6 months in the intervention group compared to the usual care group.

Conclusion: A personalized psychosocial intervention resulted in a significant improvement in carer satisfaction at 6 months but in no other outcomes. A lack of available services and barriers to social engagement may have impeded the effectiveness of this intervention. 


\section{Introduction}

Stroke can have a profound impact on the psychosocial health of stroke survivors and their carers. ${ }^{1-4}$ For example, one-third of stroke survivors experience post-stroke depression, ${ }^{5}$ twothirds of carers experience depressive or anxiety symptoms, ${ }^{3}$ and both groups report diminished quality of life (QoL). ${ }^{3,6}$ Interventions for stroke survivors and carers which have sought to improve psychosocial outcomes, such as QoL or depressive symptoms, have often emphasized rehabilitation and psychological approaches..$^{1-3,7}$ However, such approaches may neglect important social factors such as family functioning, ${ }^{8}$ social support ${ }^{9,10}$ and relational changes that occur as a result of the stroke and caring role. ${ }^{11-13}$ Diminished social functioning is associated with depression ${ }^{12}$ and diminished $\mathrm{QoL}^{14}$ in stroke survivors and is thought to increase burden ${ }^{15}$ and decrease social participation ${ }^{13}$ in carers.

There is some evidence that psychosocial interventions can improve outcomes such as QoL, ${ }^{16-19}$ depressive symptoms $s^{4,17,19-22}$ and use of health care resources ${ }^{3}$ in stroke survivors and QoL, ${ }^{1-4}$ depressive symptoms ${ }^{23-26}$ and coping in carers, ${ }^{27-30}$ but limited evidence pertaining to other important outcomes such as self-efficacy, anxiety, carer strain and carer satisfaction. ${ }^{1-4}$ However, a recent systematic review of 31 randomized controlled trials (RCTs) and a metaanalysis of 11 RCTs of psychosocial interventions for stroke survivors, carers and survivor-carer dyads reported improvements in depression, coping and anxiety. ${ }^{4}$ Meta-analysis ( 11 trials; $\mathrm{n}=1280$ ) of depressive symptoms found that in seven trials psychosocial interventions reduced depressive symptoms in stroke survivors (SMD: $-0.36,95 \% \mathrm{Cl}-0.73$ to $0.00 ; \mathrm{p}=0.05$ ) and in six trials reduced depressive symptoms in carers (SMD: $-0.20,95 \% \mathrm{Cl}-.40$ to $0.00 ; \mathrm{p}=0.05$ ). These psychosocial interventions for stroke survivors, ${ }^{22,28-30}$ carers $^{33,40}$ and survivor-carer dyads $46,47,49$ 
utilized motivational interviewing, ${ }^{29}$ transitional care, ${ }^{30}$ problem solving and psychoeducation ${ }^{22}$ and anti-depressant medication with behavioural support. ${ }^{28}$ Psychosocial interventions using social support, psychoeducation and problem-solving improved coping in carers $35,37,38,50$ and survivor-carer dyads ${ }^{46,47}$ to varying levels. One study reported statistically significant improvements in stroke survivor anxiety. ${ }^{20}$ Lessons learned from this systematic review include the challenging nature of defining, designing, implementing and evaluating psychosocial interventions for people who have a variety of support needs

Demonstrating clear evidence of the effectiveness of psychosocial interventions when such interventions by their very nature are complex poses a significant challenge. This is illustrated by the difficulty in describing and interpreting the wide variety of studies purporting to deliver and evaluate psychosocial interventions. Study designs, populations, interventions, comparators and outcomes often vary considerably. We used the lessons learned from our systematic review, ${ }^{4}$ including the difficulty in engaging stroke survivors and carers in complex interventions and authoritative policy statements ${ }^{1}$ to inform the design of a new study.

In this study we aimed to describe and evaluate the effectiveness of a novel psychosocial intervention compared to usual care for stroke survivors and carers. Primary outcomes were QoL and self-efficacy; secondary outcomes were depressive and anxiety symptoms, coping, work and social adjustment, illness perception, carer strain and carer satisfaction.

\section{Methods}


This RCT evaluated a workbook-based psychosocial intervention ( 8 one-hour weekly sessions plus 1 booster) for stroke survivors and carers compared to usual care at baseline, 3, 6 and 12 months. This intervention was based on a collaborative therapy framework, ${ }^{31}$ which emphasizes the uniqueness of each individual's recovery, and the need for services to work collaboratively with them. ${ }^{31}$ Study recruitment was from March 2016 to September 2017 with data collection concluded in September 2018 at completion of the trial. The trial was conducted and reported according to CONSORT statement. ${ }^{32}$ This trial was approved by St. Vincent's Hospital Human Research Ethics Committee (HREC-A 031/12) and overseen by a steering committee. Written informed consent from each participant was obtained. The study protocol is reported elsewhere; ${ }^{33}$ there were no significant deviations from this.

\section{Participants}

Participants were recruited from three metropolitan hospitals and community referrals in Melbourne, Australia. Eligible participants met the following criteria: diagnosis of stroke as identified from medical records or self-nominated carer of a stroke patient; 18 years or older; ability to converse in English without an interpreter or professional assistance; absence of developmental disability or amnestic disorders impairing their ability to learn from the intervention; and absence of serious comorbid illness, including severe forms of aphasia and cognitive impairment, as identified by the senior nurse.

\section{Randomization, allocation and blinding}

De-identified cases were randomly allocated to either the intervention or usual care group. Allocation was determined by a computerized block randomization sequence, conducted by a 
researcher external to the trial. Participants were randomized immediately after consent and before baseline assessments: alone if they were not consenting as a dyad; dyads were randomized together to circumvent contamination. Due to the participatory nature of the intervention and the use of self-report measures, participants and investigators could not be effectively blinded.

\section{Intervention}

In addition to usual stroke care, ${ }^{33}$ the intervention group received a program of personalized psychosocial support - Stroke Care Optimal Health Program (SCOHP) - delivered over 8 onehour weekly sessions, followed by a 'booster' session at three months (Table 1). Participants received a structured workbook and professional facilitator (psychologist) who worked with them on an individualized basis and offered flexible delivery times (weekend, afterhours) and modes (face-to-face, telephone, Skype). Participants receiving face-to-face support could choose between attending the hospital or receiving home visits. The workbook was comprised of educational information and self-management and reflective exercises which culminated in a health plan. Modules addressed: what is optimal health; I-can-do model; medication; collaborative partners and strategies; timeline activities; visioning and goal setting; building health plans; my health journal (see Table One). Survivor-carer dyads could choose to participate individually or jointly.

Enhancing self-efficacy is at the centre of SCOHP which, in turn, aims to improve selfmanagement skills and optimize mental health and the capacity to access key supports. It combines skill-building (e.g. problem solving, stress management, goal setting) with 
psychoeducational strategies, based on an individual assessment of need, tailored to each patient and carer.

\section{Usual care}

The usual care group received standard stroke care according to national stroke guidelines, ${ }^{34}$ which included secondary prevention (lifestyle modification, adherence to pharmacotherapy, diabetes management), rehabilitation (goal setting, physical activity, cognition and perception), managing complications (nutrition, oral hygiene, mood disturbance) and community participation and long-term care (self-management, return to work, support).

\section{Data collection}

As shown in Table 2, participants completed self-reported questionnaires at baseline, 3, 6, and 12 months. Only the stroke intervention group was assessed at baseline by OHP facilitators using the modified Rankin Scale as it is a clinician-measured instrument. The measurement instruments are described below (see Primary and Secondary Outcomes).

\section{Primary outcomes}

Primary outcomes were QoL and self-efficacy.

Quality of life was measured by the Australian Assessment of Quality of Life-6 Dimensions (AQoL-6D) $)^{35}$ and the 3-level EuroQoL-5-dimensions (EQ-5D-3L). ${ }^{36}$ These two instruments were also chosen to perform a health economic cost analysis (to be reported separately). The AQoL6D assesses six domains of QoL (relationships, 3 items; independent living, 4 items; coping, 3 items; mental health, 4 items; senses, 3 items; pain, 3 items) with items summed to an overall 
score; higher scores suggest better QoL. The AQoL-6D has good internal consistency. ${ }^{35}$ The EQ5D-3L ${ }^{36}$ assesses five domains of QoL: self-care, mobility, pain, usual activities, discomfort, depression and anxiety. Respondents self-rate their level of severity for each dimension using a 3-level scale. The EQ-5D-3L has an acceptable level of reliability and has been validated for with stroke survivors scoring 1.24 on the Shannon Index. ${ }^{37}$ For the study data, across all time points, the minimum Cronbach $\alpha$ score for QoL was 0.90 , indicating strong internal consistency.

Self-efficacy was measured by the General Self-Efficacy Scale (GSES), ${ }^{38}$ a 10 -item measure comprised of a 4-point scale. Items are summed giving a score range of 10 to 40; higher scores signify greater levels of self-efficacy. Internal consistency of the GSES is deemed acceptable. ${ }^{39}$ For the study data, across all time points, the minimum Cronbach $\alpha$ score for self-efficacy was 0.89 , indicating strong internal consistency.

\section{Secondary outcomes}

Secondary outcomes were anxiety and depression, coping, illness perceptions, work and social adjustment, carer strain and carer satisfaction. Each outcome measure used has reported good reliability and validity and been used widely in stroke populations.

Depression and anxiety were measured by the Hospital Anxiety and Depression Scale (HADS), ${ }^{40}$ a 14-item questionnaire that assesses depressive (7-items) and anxiety symptoms (7-items) on a 4-point Likert scale with scores between 16-21 indicating the presence of a mood disorder. ${ }^{40}$ The HADS is widely used and validated with stroke populations. ${ }^{41}$ For the study data, across all time points, the minimum Cronbach $\alpha$ score for depression and anxiety were 0.83 and 0.82 respectively, both indicating strong internal consistency. 
Coping was measured by the Brief COPE Inventory (B-COPE), ${ }^{42}$ a 28 -item questionnaire comprising 14 subscales of two items each and can be divided into adaptive (16 items) or maladaptive (12 items) coping with a 4-point rating scale. The B-COPE has good internal consistency, test-retest reliability and concurrent and convergent validity. ${ }^{43}$ For the study data, across all time points, the minimum Cronbach $\alpha$ score for adaptive and maladaptive coping were 0.82 and 0.70 , indicating strong and acceptable internal consistency respectively.

IIIness perception was measured by the Brief Illness Perception Questionnaire (BIPQ), ${ }^{44}$ a $10-$ item instrument evaluating cognitive perceptions of illness in eight dimensions: timeline, emotional response, consequences, personal control, treatment control, identity, understanding and concern. Items are assessed using an 11-point rating scale. The BIPQ had good test-retest reliability and predictive ability. ${ }^{44}$ For the study data, across all time points, the minimum Cronbach $\alpha$ score for illness perception was 0.70 , indicating acceptable internal consistency.

Work and social adjustment was measured by the Work and Social Adjustment Scale (WSAS), ${ }^{45}$ a 5-item questionnaire that assesses social functioning on a 6-point scale. The WSAS has good internal consistency. ${ }^{45}$ For the study data, across all time points, the minimum Cronbach $\alpha$ score for work and social adjustment was 0.91 , indicating strong internal consistency.

Carer strain was measured by the Modified Caregiver Strain Index (MCSI), ${ }^{46} \mathrm{a}$ 13-tem questionnaire that assesses carer strain on a 3-point scale. The MCSI has good internal reliability ${ }^{46}$ For the study data, across all time points, the minimum Cronbach $\alpha$ score for carer strain was 0.85 , indicating strong internal consistency. 
Carer satisfaction was measured by the Carer Assessment of Satisfaction Index (CASI) ${ }^{47}$ a 30item questionnaire that assesses carer satisfaction on a 4-point scale associated with the person being cared for (10 items), the carer (12 items) or interpersonal dynamics ( 8 items). The CASI has satisfactory internal consistency and construct validity. ${ }^{47}$ For the study data, across all time points, the minimum Cronbach $\alpha$ score for carer satisfaction was 0.94 , indicating strong internal consistency.

Table 2 shows the time points for administration of the primary and secondary outcome measures.

\section{Statistical analysis}

We planned to use intention-to-treat (ITT) analyses to prevent overestimation of efficacy, ${ }^{33}$ but considering the probability of missing data in this trial ITT may have underestimated the intervention effect ${ }^{48}$ decided against this. Demographic data were analyzed for group differences. A mixed effects model repeated measures (MMRM) was used to determine changes in outcomes over time and between groups (intervention/usual care).

\section{Sample size}

Power was calculated to detect a medium effect size of Cohen's $d=0.50$. This was chosen as a clinically meaningful effect size that may be compared with previous RCTs in the area of stroke management programs. ${ }^{49}$ Calculations assumed two primary outcomes (QoL and self-efficacy), four assessment points (baseline, 3, 6, 12 months), a study-wide type I error rate ( $\alpha$ ) of .05, a 
statistical test. ${ }^{50}$ Including $20 \%$ attrition, a total of 168 participants (42 carers and stroke survivors in the SCOHP and usual care groups) was the target.

\section{Results}

Of the 173 participants recruited, complete data from 137 (73 stroke survivors; 64 carers) were obtained and analyzed (Figure 1) according to the group assigned during randomization.

\section{Participant characteristics}

Participant characteristics (Tables 3 and 4) reflect the stroke population. ${ }^{51}$ Survivors in the intervention (SCOHP) and usual care groups had a mean age of 69 and 67 years respectively, with those aged 80 years or older comprising $11 \%$ and $23 \%$ of the SCOHP and usual care groups respectively, and females comprising $52 \%$ and $35 \%$ of both group respectively. One-fifth were born outside Australia. The Cronbach $\alpha$ for each outcome measure at each time point (baseline, 3, 6 and 12 months) is shown in Table 5.

No group differences were detected, with the exception of 'months since stroke': an analysis of frequencies identified this as a serendipitous effect of randomization. As per the modified Rankin Scale (mRS), ${ }^{52}$ of the stroke survivors in the SCOHP group, 1 (2\%) reported 'No symptoms', 8 (19\%) 'No significant disability', 9 (21\%) 'Slight disability', 15 (36\%) 'Moderate disability', 7 (17\%) 'Moderately severe disability', and 2 (5\%) unknown level of disability. It was not possible to use the mRS in the usual care group.

Carers were aged between 31 to 89 (mean 65) and 26 to 87 (mean 61) years in the SCOHP and usual care groups respectively. Carers were usually female (74\% SCOHP; $79 \%$ usual 
care) and the partner of a stroke survivor (79\% SCOHP; 73\% usual care). In comparison, stroke survivors and carers were most often married, living in their own home and had completed further education after high school.

\section{Effects of the intervention}

The results (Table 6) between groups and over time did not show a significant improvement in the primary outcomes, QoL or self-efficacy. However, there was a significant improvement in carer satisfaction (in relation to the person being cared for) in favour of the SCOHP group at 6 months. There were no other statistically significant findings.

\section{Discussion}

In a randomized controlled trial of a psychosocial intervention (SCOHP) for stroke survivors and carers, we found no evidence that it improved between groups and over time the primary outcomes of QoL and self-efficacy. Nor, with the exception of carer satisfaction, did SCOHP improve secondary outcomes of depressive and anxiety symptoms, coping, illness perceptions, work and social adjustment and carer strain in stroke survivors and carers. This accords with previous trials evaluating interventions to improve both of these outcomes in this population, ${ }^{19,30,53-55}$ with only a few studies showing significant improvements in QoL. ${ }^{16-18}$ Strengths of this trial include basing the intervention on prior trials in our systematic review and our own pilot data, conducting an RCT, having a control group comprising survivors and carers, and obtaining some new Australian specific data.

Though QoL is deemed an important outcome in this population, its improvement has often proven elusive and this may help explain these neutral findings. ${ }^{1-4}$ Notable exceptions are 
psychosocial and educational interventions that have been used in conjunction with physical rehabilitation in hospital and community settings. ${ }^{16,17}$ For example, an RCT of 243 stroke survivors in the UK evaluating a community-based exercise and education scheme held twice weekly for eight weeks for stroke survivors and carers, facilitated by volunteers and exercise instructor and using group work and peer support, reported improvements in QoL. ${ }^{16}$ Another RCT of 101 community-living stroke survivors in Canada evaluating a 12-month specialized rehabilitation strategy involving an interprofessional team reported improvements in QoL. ${ }^{17}$ While the focus, content, duration, intensity and mode of delivery of interventions varied in these two trials, consideration may need to be given to incorporating such approaches into our intervention to examine whether it impacts on QoL and other outcomes in survivors and carers. SCOHP did not use rehabilitation techniques and thus may have not fully met the support needs of the participants, resulting in largely neutral results. Carers' QoL is likely impacted by their partner's stroke ${ }^{56-59}$ and may be compounded by carers' lack of routine access to health services which, in turn, likely increases burden, ${ }^{60}$ including psychological, ${ }^{61}$ and exacerbates their QoL. ${ }^{62}$ intervention in order to strengthen the participants' belief that they can accomplish chosen tasks in order to help them better self-manage their stroke/carer role. Significant improvements in self-efficacy have been reported in self-management and education interventions in other chronic diseases, including cardiovascular disease and diabetes, ${ }^{63-65}$ but not stroke. ${ }^{19,30,53,54}$ The lack of effectiveness of SCOHP on this outcome may be due to an impoverished service environment. For example, completion of the SCOHP modules culminates 
in a health plan. However, a number of barriers to participants accessing services during the trial became apparent, including: limited availability of stroke/carer-specific services (e.g. Stroke Foundation, Stroke Association, Carers Australia); $34,66,67$ most stroke survivors no longer qualifying for important adult services such as the National Disability Insurance Scheme (NDIS) ${ }^{68}$ and adult mental health services ${ }^{69}$ due to their age; and those requiring additional support services (e.g. neurology clinic, department of housing) often encountering complex referral pathways and extensive wait times. Thus participants may not benefit from these services within the trial period. Future interventions should train facilitators in stroke-specific services/referral pathways to improve access and advocate for greater resources.

We found no evidence that SCOHP had a significant effect on depression and anxiety, coping, illness perceptions, work and social adjustment, carer strain or carer satisfaction, findings consistent with other trials of such interventions in this population. ${ }^{1-3}$ Possible explanations for a lack of effectiveness may relate to study population, contextual factors or intervention content, mode of delivery or dose. This warrants further exploration.

Our finding of a statistically significant difference in carer satisfaction (regarding the person being cared for) in favour of SCOHP is not wholly unsurprising. Considering the scant resources available to carers in countries like Australia ${ }^{62,63}$ and the additional responsibilities carers take on (e.g., medication administration, showering, household duties), SCOHP may have helped alleviate this burden and increased carer satisfaction by enhancing their self-efficacy. However, it is no surprise that carers feel burdened and overwhelmed, ${ }^{54,57,60,64,65,70}$ which may explain why carers were far more difficult to identify, recruit and retain than stroke survivors, with carer attrition higher than that of stroke survivors and 'failure to return the questionnaire' 
being offered as the principal reason. The level of participation expected of them in SCOHP may have exceeded their capacity. This is an important consideration for participation in future trials.

Depression and anxiety contribute substantially to the disease burden of stroke survivors and carers. ${ }^{4,60,71}$ There is some evidence that psychosocial interventions can reduce depressive symptoms in stroke survivors ${ }^{4,17,21,22}$ and carers $^{4,23,25}$ but little evidence pertaining to its impact on anxiety. ${ }^{4,20}$ However, our trial included a high percentage of stroke survivors aged 80 years and older (usual care $22 \%$, intervention $12 \%$ ), a population with increased disability which is a risk factor for post-stoke depression. ${ }^{71}$ Indeed, older cohorts such as ours may experience declining mobility and diminished functioning which can inhibit social participation and compound depression. Thus, we were surprised that our intervention had no effect in reducing depressive symptoms, which contrasts with the findings from a recent systematic review and meta-analysis which showed that psychosocial interventions reduced depressive symptoms in stroke survivors and their carers. ${ }^{4}$

In terms of the intervention, participants were offered a variety of modes of delivery, but we found that in most instances they availed themselves of face-to-face sessions, invariably during weekdays. An earlier review of psychosocial interventions for stroke survivors suggested that between five to nine sessions is optimal, though informal feedback from our participants indicated that on-going support was required. ${ }^{1}$ Though it is unlikely that mode of delivery made a difference to any outcome, this is an avenue worth further exploration. Future trials should include stroke survivors and carers in their project advisory teams to inform the design, 
production and conduct of the study, with special regard to the selection of outcome measures taking into consideration any burden that they may impose.

It should be acknowledged that the trial was underpowered. We aimed to recruit 168 participants (42 survivors and carers in each group) and, although we exceeded this number, complete data were obtained from only 137 of them. Thus, with the exception of stroke survivors in the SCOHP group, there were insufficient numbers of participants (survivors and carers) in the other groups to meet our target sample size. This was despite repeated attempts employing various strategies to enhance recruitment, including reminders. Feedback from participants indicated that lengthy questionnaires, difficulty in posting them and the intensity of physical rehabilitation schedules contributed to drop outs and failure to return questionnaires.

Despite the lack of effectiveness of our intervention, the trial had a number of strengths. First, it was conducted and reported in accordance with CONSORT guidelines. ${ }^{32}$ Second, this comprehensive psychosocial intervention is among the first to be offered to stroke survivors and carers in Australia and, as such, has contributed new knowledge pertaining to a 'real world' practice environment, including identifying deficiencies in service organization and delivery, which is of great import to local clinicians and researchers. Third, the trial was analyzed using a robust strategy, which featured MMRM analysis and contributed new knowledge regarding the characteristics of stroke service users.

The findings from this trial should be interpreted in light of the following limitations. First, this preliminary RCT was small in size and experienced significant attrition rates which is 
likely influenced by the disability associated with stroke survivors and the heavy burden among carers; larger trials are required to confirm or refute these findings. Also, some imbalance in randomization was noted. Blinding of outcomes assessors (i.e. participants) or staff was impossible and they could discern who was or was not receiving usual care; although this is a limitation it is a consequence of conducting trials in a real life setting. It is probable that too many outcome measures were included, which imposed an unrealistic burden on participants and resulted in a reduced sample. Difficulties were also acknowledged in using clinician-based measures, for example the mRS could not be collected in the usual care group. Future trials should consider the impact of dyadic relationships amongst participants and analyze accordingly. Finally, it was noted that there was a significant difference in the time elapsed since stroke between the intervention and usual care group; this could have impacted the findings.

\section{Conclusion}

Stroke survivors and their carers have many complex and unresolved needs. Interventions aimed at improving their psychosocial health should focus on preferred choice of intervention, including its mode, content and duration of delivery, and the most appropriate outcomes. Measures of patient and carer experience, which would bolster evidence of effectiveness, should also be incorporated.

\section{Sources of funding}

This study was supported by a Australian Government's Collaborative Research Network grant.

\section{Disclosures}



None.

377 Clinical Trial Registration: ACTRN12615001046594. Registered on 7 October 2015

378

379

380

381

382

383

384

385

386

387

388

389 
400

401

402

403

404

405

406

407

408

409

410

411

412

\section{References}

1. Bakas T, Clark PC, Kelly-Hayes M, King RB, Lutz BJ, Miller EL; American Heart Association Council on Cardiovascular and Stroke Nursing and the Stroke Council. Evidence for stroke family caregiver and dyad interventions: A statement for healthcare professionals from the American Heart Association and American Stroke Association. Stroke. 2014;45:2836-2852. doi: 10.1161/STR.0000000000000033

2. Bakas T, McCarthy M, Miller ET. Update on the state of the evidence for stroke family caregiver and dyad interventions. Stroke. 2017;48:e122-e125. doi:

10.1161/STROKEAHA.117.016052

3. Cheng HY, Chair SY, Chau JPC. The effectiveness of psychosocial interventions for stroke family caregivers and stroke survivors: A systematic review and meta-analysis. Patient Education and Counseling. 2014;95:30-44. doi: 10.1016/j.pec.2014.01.005

4. Minshall C, Pascoe MC, Thompson DR, Castle DJ, McCabe M, Chau JPC, Jenkins Z, Cameron J, Ski CF. Psychosocial interventions for stroke survivors, carers and survivorcarer dyads: A systematic review and meta-analysis. Topics in Stroke Rehabilitation. 2019;26:554-564. doi: 10.1080/10749357.2019.1625173

5. Towfighi A, Ovbiagele B, El Husseini N, Hackett ML, Jorge RE, Kissela BM, Mitchell PH, Skolarus LE, Whooley MA, Williams LS. Poststroke depression: A scientific statement for healthcare professionals from the American Heart Association/American Stroke Association. Stroke. 2017;48:e30-e43. doi: 10.1161/STR.0000000000000113 
6. van Mierlo M, van Heugten C, Post MWM, Hoekstra T, Visser-Meily A. Trajectories of health-related quality of life after stroke: Results from a one-year prospective cohort study. Disability and Rehabilitation. 2018;40:997-1006. doi:

$10.1080 / 09638288.2017 .1292320$

7. Eldred C, Sykes C. Psychosocial interventions for carers of survivors of stroke: A systematic review of interventions based on psychological principles and theoretical frameworks. British Journal of Health Psychology. 2008;13:563-581.

8. Clark MS, Smith DS. Changes in family functioing for stroke rehabilitation patients and their families. International Journal of Rehabilitation Research. 1999;22:171-179.

9. Volz M, Möbus J, Letsch C, Werheid K. The influence of early depressive symptoms, social support and decreasing self-efficacy on depression 6 months post-stroke. Journal of Affective Disorders. 2016;206:252-255. doi: 10.1016/j.jad.2016.07.041

10. Kruithof WJ, van Mierlo ML, Visser-Meily JMA, van Heugten CM, Post MWM. Associations between social support and stroke survivors' health-related quality of life A systematic review. Patient Education and Counseling. 2013;93:169-176. doi: 10.1016/j.pec.2013.06.003

11. Greenwood N, Mackenzie A, Cloud GC, Wilson N. Informal carers of stroke survivorsfactors influencing carers: A systematic review of quantitative studies. Disability and Rehabilitation. 2008;30:1329-1349. doi: 10.1080/09638280701602178 
452

453

454

455

456

457

458

459

460

461

462

463 464

12. Greenwood N, Mackenzie A, Cloud GC, Wilson N. Informal primary carers of stroke survivors living at home - challenges, satisfactions and coping: A systematic review of qualitative studies. Disability and Rehabilitation. 2009;31:337-351. doi: $10.1080 / 09638280802051721$

13. Lou S, Carstensen K, Jørgensen CR, Nielsen CP. Stroke patients' and informal carers' experiences with life after stroke: An overview of qualitative systematic reviews. Disability and Rehabilitation. 2017;39:301-313. doi: 10.3109/09638288.2016.1140836

14. Northcott S, Moss B, Harrison K, Hilari K. A systematic review of the impact of stroke on social support and social networks: Associated factors and patterns of change. Clinical Rehabilitation. 2015;30:811-831. doi: 10.1177/0269215515602136

15. Rigby $\mathrm{H}$, Gubitz G, Phillips S. A systematic review of caregiver burden following stroke. International Journal of Stroke. 2009:4:285-292. doi: 10.1111/j.1747-4949.2009.00289

16. Harrington R, Taylor G, Hollinghurst S, Reed M, Kay H, Wood VA. A community-based exercise and education scheme for stroke survivors: A randomized controlled trial and economic evaluation. Clinical Rehabilitation. 2010;24:3-15. doi: $10.1177 / 0269215509347437$

17. Markle-Reid M, Orridge C, Weir R, Browne G, Gafni A, Lewis M, Walsh M, Levy C, Daub S, Brien H, Roberts J, Thabane L. Interprofessional stroke rehabilitation for stroke survivors using home care. Canadian Journal of Neurological Sciences. 2011;38:317-334. 
18. Robinson-Smith G, Harmer C, Sheeran R, Bellino Vallo E. Couples' coping after stroke - A pilot intervention study. Rehabilitation Nursing. 2016;41:218-229. doi: 10.1002/rnj.213

19. Wong FKY, Yeung SM. Effects of a 4-week transitional care programme for discharged stroke survivors in Hong Kong: A randomised controlled trial. Health and Social Care in the Community. 2015;23:619-631. doi: 10.1111/hsc.12177

20. Fang $\mathrm{Y}, \mathrm{Mpofu} \mathrm{E}$, Athanasou J. Reducing depressive or anxiety symptoms in post-stroke patients: Pilot trial of a constructive integrative psychosocial intervention. International Journal of Health Sciences. 2017;11:53-58.

21. Watkins CL, Auton MF, Deans CF, Dickinson HA, Jack Cl, Lightbody CE, Sutton CJ, van den Broek MD, Leathley MJ. Motivational interviewing early after acute stroke: $A$ randomized, controlled trial. Stroke. 2007;38:1004-1009. doi: 10.1161/01.STR.0000258114.28006.d7

22. Mitchell PH, Veith RC, Becker KJ, Buzaitis A, Cain KC, Fruin M, Tirschwell D, Teri L. Brief psychosocial-behavioral intervention with antidepressant reduces poststroke depression significantly more than usual care with antidepressant. Living well with stroke: Randomized controlled trial. Stroke. 2009;40:3073-3078. doi: 10.1161/STROKEAHA.109.549808

23. Grant JS, Elliott TR, Weaver M, Bartolucci AA, Giger JN. Telephone intervention with family caregivers of stroke survivors after rehabilitation. Stroke. 2002;33:2060-2065. doi: 10.1161/01.str.0000020711.38824.e3 
491

492

493

494

495

496

497

498

499

500

501

502

503

504

505

506

507

508

509

510

511

512

513

514

515

516

24. Ostwald SK, Godwin KM, Cron SG, Kelley CP, Hersch G, Davis S. Home-based psychoeducational and mailed information programs for stroke-caregiving dyads postdischarge: A randomized trial. Disability and Rehabilitation. 2014;36:55-62.

25. Smith GC, Egbert N, Dellman-Jenkins M, Nanna K, Palmieri PA. Reducing depression in stroke survivors and their informal caregivers: A randomized clinical trial of a web-based intervention. Rehabilitation Psychology. 2012;57:196-206. doi: 10.1037/a0029587

26. Bakas T, Austin J, Habermann B, Jessup N, McLennon S, Mitchell P, Morrison G, Yang Z, Stump TE, Weaver MT. Telephone assessment and skill-building kit for stroke caregivers: A randomized controlled clinical trial. Stroke. 2015;46:3478-3487. doi:

10.1161/STROKEAHA.115.011099

27. Cheng HY, Chair SY, Chau JPC. Effectiveness of a strength-oriented psychoeducation on caregiving competence, problem-solving abilities, psychosocial outcomes and physical health among family caregiver of stroke survivors: A randomised controlled trial. International Journal of Nursing Studies. 2018;87:84-93. doi:

10.1016/j.ijnurstu.2018.07.005

28. Inci FH, Temel AB. The effect of the support program on the resilience of female family caregivers of stroke patients: Randomized controlled trial. Applied Nursing Research. 2016;32:233-240. doi: 10.1016/j.apnr.2016.08.002

29. van den Heuvel ET, de Witte LP, Nooyen-Haazen I, Sanderman R, Meyboom-de Jong B. Short-term effects of a group support program and an individual support program for caregivers of stroke patients. Patient Education and Counseling. 2000;40:109-120. 
30. van den Heuvel ET, Witte LP, Stewart RE, Schure LM, Sanderman R, Meyboom-de Jong B. Long-term effects of a group support program and an individual support program for informal caregivers of stroke patients: Which caregivers benefit the most? Patient Education and Counseling. 2002;47:291-299.

31. Castle DJ, Gilbert M. Collaborative therapy: Framework for mental health. British Journal of Psychiatry 2006;189:467. doi: 10.1192/bjp.189.5.467

32. Schulz KF, Altman DG, Moher D, CONSORT Group. Consort 2010 statement: Updated guidelines for reporting parallel group randomised trials. British Medical Journal. 2010;340:c332. doi: 10.1136/bmj.c332

33. Brasier C, Ski CF, Thompson DR, Cameron J, Brien CL, Lautenschlager NT, Gonzales G, Hseuh YS, Moore G, Knowles SR, Rossell SL, Haselden R, Castle DJ. The stroke and carer optimal health program (SCOHP) to enhance psychosocial health: Study protocol for a randomized controlled trial. Trials. 2016;17. doi: 10.1186/s13063-016-1559-y

34. Stroke Foundation. Clinical Guidelines for Stroke Management 2017. Stroke Foundation: Melbourne; 2017.

35. Allen J, Inder KJ, Lewin TJ, Attia JR, Kelly BJ. Construct validity of the Assessment of Quality of Life -6D (AQoL-6D) in community samples. Health and Quality of Life Outcomes. 2013;11:61. doi: 10.1186/1477-7525-11-61

36. Rabin R, de Charro F. EQ-5D: A measure of health status from the EuroQol Group. Annals of Medicine. 2001;33. doi: 10.3109/07853890109002087 
544 37. Janssen MF, Pickard AS, Golicki D, Gudex C, Niewada M, Scalone L, Swinburn P, Busschbach J. Measurement properties of the EQ-5D-5L compared to the EQ-5D-3L across eight patient groups: A multi-country study. Quality of Life Research. 2013;22:1717-1727. doi: 10.1007/s11136-012-0322-4.

38. Schwarzer R, Jerusalem M. Generalized self-efficacy scale. In: Measures in Health Psychology: A User's Portfolio. Causal and Control Beliefs. (pp. 35-37) Eds: J Weinman, S Wright, M Johnston. NFER Nelson: Windsor; 1995.

552

553

554

555

556

557

558

559

560

563

564

565

566

567

39. Scholz U, Gutiérrez Doña B, Sud S, Schwarzer R. Is general self-efficacy a universal construct? Psychometric findings from 25 countries. European Journal of Psychological Assessment. 2002;18:242-251. doi: 10.1027//1015-5759.18.3.242

40. Snaith RP. The Hospital Anxiety and Depression Scale. Health and Quality of Life Outcomes. 2003;1:29.

41. Burton L, Tyson S. Screening for mood disorders after stroke: A systematic review of psychometric properties and clinical utility. Psychological Medicine. 2015;45:29-49. doi: http://dx.doi.org/10.1017/S0033291714000336

42. Carver C. You want to measure coping but your protocol's too long: Consider the Brief COPE. International Journal of Behavioral Medicine. 1997;4:92-100. doi: 10.1207/s15327558ijbm0401_6 
43. Cooper C, Katona C, Livingston G. Validity and reliability of the Brief COPE in carers of people with dementia: The LASER-AD Study. Journal of Mental Nervous Disorders. 2008;196:834-843.

44. Broadbent E, Petrie KJ, Main J, Weinman J. The Brief Illness Perception Questionnaire. Journal of Psychosomatic Research. 2006;60:631-637. doi: http://dx.doi.org/10.1016/i.jpsychores.2005.10.020

45. Mundt JC, Marks IM, Shear MK, Greist JH. The Work and Social Adjustment Scale: A simple measure of impairment in functioning. British Journal of Psychiatry. 2001;180:461-464.

46. Thornton M, Travis SS. Analysis of the reliability of the Modified Caregiver Strain Index. Journals of Gerontology Series B: Psychological Sciences; Social Sciences. 2003;58:S127S132.

47. McKee K, Spazzafumo L, Nolan M, Wojszel B, Lamura G, Bien B. Components of the difficulties, satisfactions and management strategies of carers of older people: A principal component analysis of CASI-CASI-CAMI. Aging and Mental Health. 2009;13:255-264. doi: 10.1080/13607860802342219

48. Shrier I, Verhagen E, Stovitz SD. The intention-to-treat analysis is not always the conservative approach. American Journal of Medicine. 2017;130:867-871. doi: 10.1016/j.amjmed.2017.03.023 
593

594

595

596

597

598

599

600

601

602

603

604

605

606

607

608

609

610

611

612

613

614

615

616

617

618

49. Bour A, Rasquin S, Boreas A, Limburg M, Verhey F. How predictive is the MMSE for cognition performance after stroke. Journal of Neurology. 2010;257:630-637. doi: 10.1007/s00415-009-5387-9

50. Diggle P, Heagerty P, Liang K, Zeger S. Analysis of Longitudinal Data. 2nd ed., Oxford: Oxford University Press; 2002.

51. Benjamin JE, Blaha JM, Chiuve ES, Cushman RM, Das DS, Deo RR, et al. Heart disease and stroke statistics-2017 update: A report from the American Heart Association. Circulation. 2017;135:e146-e603. doi: 10.1161/CIR.0000000000000485

52. Banks JL, Marotta CA. Outcomes validity and reliability of the Modified Rankin Scale implications for stroke clinical trials: A literature review and synthesis. Stroke. 2007;38:1091-1096. doi: 10.1161/01.STR.0000258355.23810.c6

53. Glass TA, Berkman LF, Hiltunen EF, Furie K, Glymour MM, Fay ME, Are J. The Families in Recovery From Stroke Trial (FIRST): Primary study results. Psychosomatic Medicine. 2004;66:889-897. doi: 10.1097/01.psy.0000146326.01642.ca

54. Hoffmann T, Ownsworth T, Eames S, Shum D. Evaluation of brief interventions for managing depression and anxiety symptoms during early discharge period after stroke: A pilot randomized controlled trial. Topics In Stroke Rehabilitation. 2015;22:116-126. doi: $10.1179 / 1074935714 Z .0000000030$

55. Kendall E, Catalano T, Kuipers P, Posner N, Buys N, Charker J. Recovery following stroke: The role of self-management education. Social Science and Medicine. 2007;64:735-746. 
620 56. Camak, DJ. Addressing the burden of stroke caregivers: A literature review. Journal of Clinical Nursing. 2015;24:2376-2382. doi: 10.1111/jocn.12884

622

623

624

625

626

627

628

629

630

631

632

633

634

635

636

637

638

639

640

641

642

643

57. Ski CF, Castle DJ, Lautenschlager NT, Moore G, Thompson DR. Caring for caregivers after a stroke. International Psychogeriatrics. 2015;27:1-4. doi: 10.1017/S1041610214002385

58. Akosile CO, Banjo TO, Okoye EC, Ibikunle PO, Odole AC. Informal caregiving burden and perceived social support in an acute stroke care facility. Health and Quality of Life Outcomes. 2018;16doi: 10.1186/s12955-018-0885-z

59. Ski C, O'Connell B. Stroke: The increasing complexity of carer needs. Journal of Neuroscience Nursing. 2007;39:172-179.

60. Pucciarelli G, Vellone E, Savini S, Simeone S, Ausili D, Alvaro R, Lee CS, Lyons KS. Roles of changing physical function and caregiver burden on quality of life in stroke: A longitudinal dyadic analysis. Stroke. 2017;48:733-739. doi: 10.1161/STROKEAHA.116.014989

61. Loh AZ, Tan JS, Zhang MW, Ho RC. The global prevalence of anxiety and depressive symptoms among caregivers of stroke survivors. Journal of the American Medical Directors Association. 2017;18:111-116. doi: 10.1016/j.jamda.2016.08.014

62. van Mierlo ML, Schröder C, van Heugten CM, Post MWM, de Kort PLM, Visser-Meily JMA. The influence of psychological factors on health-related quality of life after stroke: 
650

651

652

653

654

655

656

657

658

659

660

661

662

663

664

665

666

667

668

A systematic review. International Journal of Stroke. 2014;9:341-348. doi:

10.1111/ijs.12149.

63. Hannah K, Holly M. The role of self-efficacy in cardiovascular disease self-management: A review of effective programs. Patient Intelligence. 2010;2:33-44. doi.org/10.2147/PI.S12642

64. Sol BGM, van Der Graaf $Y$, van Petersen R, Visseren FU. The effect of self-efficacy on cardiovascular lifestyle. European Journal of Cardiovascular Nursing. 2011;10:180-186. doi: 10.1016/j.ejcnurse.2010.06.005

65. Sharoni SKA, Rahman HA, Minhat HS, Shariff-Ghazali S, Ong MHA. The effects of selfefficacy enhancing program on foot self-care behaviour of older adults with diabetes: A randomised controlled trial in elderly care facility, Peninsular Malaysia. PLOS ONE. 2018;13:e0192417. doi: 10.1371/journal.pone.0192417

66. Stroke Association of Victoria. The Stroke Association of Victoria. [cited 19/02/2019]; Available from: http://www.strokeassociation.com.au/index.html.

67. Carers Australia. Carers Australia. [cited 19/02/2019]; Available from: http://www.carersaustralia.com.au/about-us/contact/

68. Commonwealth of Australia. 2010-2020 National Disability Strategy - An Initiative of the Council of Australian Governments. Department of Social Services: Canberra; 2011. 
669

670

671

672

673

674

675

676

677

678

679

680

681

682

683

684

685

686

687

688

689

690

691

692

693

694

695

69. Victoria State Goverment. Victoria's 10-year Mental Health Plan. Department of Health and Humnan Services; Melbourne; 2015.

70. Ski C, O'Connell B. Caring for carers: Stroke survivors in the community. Australian Nursing Journal. 2005;13:31.

71. Robinson, RG, Jorge RE. Post-stroke depression: A review. American Journal of Psychiatry. 2016;173:221-231. doi: doi:10.1176/appi.ajp.2015.15030363

8

(1) 
Table 1. Content and structure of the intervention

697

\begin{tabular}{|c|c|c|c|}
\hline Session & Theme & Focus & Purpose \\
\hline 1 & What is health? & $\begin{array}{l}\text { Optimal health } \\
\text { wheel }\end{array}$ & $\begin{array}{l}\text { Increase ability to understand health as } \\
\text { comprised of social, physical, emotional, } \\
\text { intellectual, vocational and spiritual } \\
\text { dimensions }\end{array}$ \\
\hline 2 & I-can-do model A & Health plan A & Explore strengths and vulnerabilities \\
\hline 3 & I-can-do model B & Health plan B & Explore strengths and vulnerabilities \\
\hline 4 & Medication & $\begin{array}{l}\text { Medication } \\
\text { monitoring }\end{array}$ & $\begin{array}{l}\text { Improve knowledge and efficacy regarding } \\
\text { medication }\end{array}$ \\
\hline 5 & $\begin{array}{l}\text { Collaborative } \\
\text { partners/strategies }\end{array}$ & $\begin{array}{l}\text { Identifying } \\
\text { partners and } \\
\text { support }\end{array}$ & $\begin{array}{l}\text { Consider supports which could be included in } \\
\text { the health plan }\end{array}$ \\
\hline 6 & $\begin{array}{l}\text { Change } \\
\text { enhancement }\end{array}$ & $\begin{array}{l}\text { Understanding } \\
\text { the past; planning } \\
\text { for the future }\end{array}$ & $\begin{array}{l}\text { Contextualize past and allow for new } \\
\text { possibilities to be conceived and planned }\end{array}$ \\
\hline 7 & Goal setting & $\begin{array}{l}\text { Planning for the } \\
\text { future }\end{array}$ & $\begin{array}{l}\text { Emphasize role of autonomy and choice in } \\
\text { adapting post-stroke }\end{array}$ \\
\hline 8 & Health plans & $\begin{array}{l}\text { Advanced care } \\
\text { planning }\end{array}$ & $\begin{array}{l}\text { Consolidate past } 8 \text {-weeks into a health care } \\
\text { plan designed by participant }\end{array}$ \\
\hline 9 & Booster & Reflect and revise & $\begin{array}{l}\text { Reflect on health plan and its efficacy. } \\
\text { Opportunity to talk through additional } \\
\text { changes/adjustments to plan and process }\end{array}$ \\
\hline
\end{tabular}

698 
Table 2. Primary and secondary outcome measures and time points

708

Stroke survivor

\section{Carer}

710

T1 T2 T3 T4

Outcome measure

713

AQoL-6D

714

EQ-5D-3L

715

GSES

716

HADS

Brief COPE

BIPQ

WSAS

$x \quad x$

$x \quad x \quad x$

$\begin{array}{llll}x & x & x\end{array}$

$x \quad x \quad x$

$\begin{array}{llll}x & X & X\end{array}$

$x \quad x \quad x$

$x \quad x \quad x \quad x$

$x \quad x \quad x$

$x \quad x \quad x$

$x \quad x \quad x$

$x \quad x \quad x \quad x$

718

$x \quad x$

719

MCSI

$x \quad x \quad x$

$x \quad x \quad x \quad x$

$x \quad x \quad x$

CASI

$x \quad x$

$x \quad x$

722

Key: T1 Baseline; T2 3 months; T3 6 months; T4 12 months; AQoL-6D Assessment of Quality of Life-6 Dimensions; EQ-5D-3L European Quality of Life-5-Dimensions; GSES General Self-Efficacy Scale; HADS Hospital Anxiety and Depression Scale; Brief COPE Brief version of the COPE Inventory; BIPQ Brief Illness Perception Questionnaire; WSAS Work and Social Adjustment Scale; MCSI Modified Caregiver Strain Index; CASI Carer Assessment of Satisfaction Index 
Table 3. Baseline characteristics of stroke survivors in the SCOHP and usual care groups

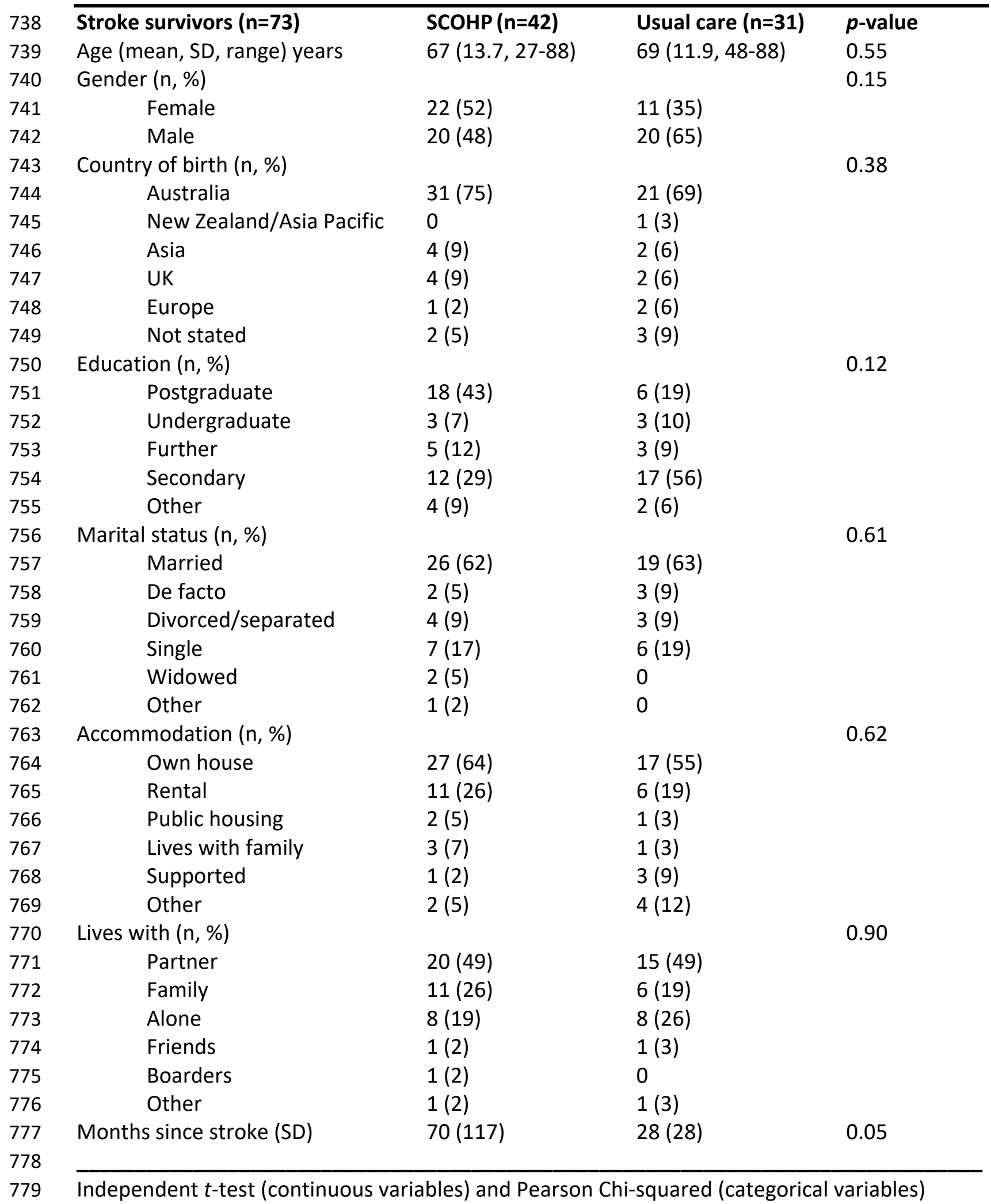


800

801

802

803

804

805

806

807

808

809

810

811

812

813

814

815

816

817

818

819

820

821

822

823

Table 4. Baseline characteristics of carers in the SCOHP and usual care groups

\begin{tabular}{|c|c|c|c|}
\hline Carers $(n=64)$ & $\operatorname{SCOHP}(n=35)$ & Usual care $(n=29)$ & $p$-value \\
\hline Age (mean, SD, range) years & $65(13.4,31-89)$ & $61(14,26-87)$ & 0.32 \\
\hline Gender (n, \%) & & & 0.63 \\
\hline Female & $23(74)$ & $23(79)$ & \\
\hline Male & $9(26)$ & $6(21)$ & \\
\hline Country of birth (n, \%) & & & 0.39 \\
\hline Australia & $24(69)$ & $22(76)$ & \\
\hline New Zealand/Asia Pacific & $4(12)$ & 0 & \\
\hline Asia & $1(3)$ & $1(3)$ & \\
\hline UK & $3(8)$ & $2(7)$ & \\
\hline Europe & $3(8)$ & $2(7)$ & \\
\hline Not stated & 0 & $2(7)$ & \\
\hline Education (n, \%) & & & 0.89 \\
\hline Postgraduate & $10(30)$ & $8(28)$ & \\
\hline Undergraduate & $8(23)$ & $6(21)$ & \\
\hline Further & $2(6)$ & $2(7)$ & \\
\hline Secondary & $10(30)$ & $11(37)$ & \\
\hline Other & $5(11)$ & $2(7)$ & \\
\hline Marital status (n, \%) & & & 0.25 \\
\hline Married & $28(79)$ & $17(59)$ & \\
\hline De facto & $2(6)$ & $6(20)$ & \\
\hline Divorced/separated & $3(9)$ & $4(14)$ & \\
\hline Single & $1(3)$ & $2(7)$ & \\
\hline Other & $1(3)$ & 0 & \\
\hline Accommodation ( $n, \%)$ & & & 0.21 \\
\hline Own house & $26(74)$ & $15(52)$ & \\
\hline Rental & $4(11)$ & $7(25)$ & \\
\hline Public housing & 0 & $2(7)$ & \\
\hline Lives with family & $3(9)$ & $1(3)$ & \\
\hline Supported & $1(3)$ & $1(3)$ & \\
\hline Other & $1(3)$ & $3(10)$ & \\
\hline Lives with (n, \%) & & & 0.13 \\
\hline Partner & $20(56)$ & $14(49)$ & \\
\hline Family & $10(29)$ & $9(31)$ & \\
\hline Alone & $2(6)$ & $6(20)$ & \\
\hline Other & $3(9)$ & $1(3)$ & \\
\hline \multicolumn{3}{|l|}{ Relationship to stroke survivor (n, \%) } & 0.58 \\
\hline Partner & $28(79)$ & $21(73)$ & \\
\hline Parent & $3(9)$ & $6(21)$ & \\
\hline Sibling & $1(3)$ & $1(3)$ & \\
\hline Other & $1(3)$ & $1(3)$ & \\
\hline
\end{tabular}

Independent $t$-test (continuous variables) and Pearson Chi-squared (categorical variables) 
Table 5. The Cronbach $\alpha$ for each outcome (measure) at the four time points

\begin{tabular}{lllll}
\hline Outcome & Baseline & $\mathbf{3}$ months & $\mathbf{6}$ months & $\mathbf{1 2}$ months \\
QoL (AQoL) & 0.91 & 0.91 & 0.92 & 0.90 \\
Self-efficacy (GSES) & 0.89 & 0.93 & 0.92 & 0.95 \\
Depressive symptoms (HADS) & 0.83 & 0.86 & 0.90 & 0.86 \\
Anxiety symptoms (HADS) & 0.84 & 0.82 & 0.85 & 0.90 \\
Adaptive coping (Brief COPE) & 0.86 & 0.83 & 0.87 & 0.82 \\
Maladaptive coping (Brief COPE) & 0.70 & 0.70 & 0.72 & 0.73 \\
Illness perception (BIPQ) & 0.70 & 0.69 & 0.68 & 0.71 \\
Work and social adjustment (WSAS) & 0.91 & 0.93 & 0.93 & 0.94 \\
Caregiver strain (MCSI) & 0.85 & 0.89 & 0.89 & 0.89 \\
Carer satisfaction (CASI) & 0.96 & 0.94 & 0.95 & 0.96 \\
& & & & \\
\hline
\end{tabular}

Key: AQoL-6D Assessment of Quality of Life-6 Dimensions; GSES General Self-Efficacy Scale; HADS Hospital Anxiety and Depression Scale; Brief COPE Brief version of the COPE Inventory; BIPQ Brief Illness Perception Questionnaire; WSAS Work and Social Adjustment Scale; MCSI Modified Caregiver Strain Index; CASI Carer Assessment of Satisfaction Index 
861

862

863

864

865

866

867

868

869

870

871

872

873

874

875

876

877

878

879

880

881

882

883

884

885

886

887

888

889

890

891

892

893

894

895

896

897

898

899

900

901

902

903

904

Table 6. The effect of the intervention (SCOHP) between groups and over time

\begin{tabular}{|c|c|c|c|c|c|c|}
\hline \multirow[b]{2}{*}{$\begin{array}{l}\text { Outcome } \\
\text { (measure) }\end{array}$} & \multicolumn{3}{|c|}{ Stroke survivor } & \multicolumn{3}{|l|}{ Carer } \\
\hline & $\begin{array}{l}\text { SCOHP } \\
\text { Mean (SD) }\end{array}$ & $\begin{array}{l}\text { UC } \\
\text { Mean (SD) }\end{array}$ & $\begin{array}{l}p \text { - } \\
\text { value }\end{array}$ & $\begin{array}{l}\text { SCHOP } \\
\text { Mean (SD) }\end{array}$ & $\begin{array}{l}\text { UC } \\
\text { Mean (SD) }\end{array}$ & $\begin{array}{l}p \text { - } \\
\text { value }\end{array}$ \\
\hline \multicolumn{7}{|l|}{ Primary: } \\
\hline \multicolumn{7}{|c|}{ Quality of life (AQOL) } \\
\hline Baseline & $0.61(0.20)$ & $0.63(0.24)$ & 0.71 & $0.71(0.19)$ & $0.72(0.21)$ & 0.96 \\
\hline 3 months & $0.59(0.18)$ & $0.62(0.27)$ & 0.63 & $0.77(0.13)$ & $0.71(0.19)$ & 0.25 \\
\hline 6 months & $0.58(0.18)$ & $0.63(0.27)$ & 0.40 & $0.70(0.16)$ & $0.72(0.22)$ & 0.74 \\
\hline 12 months & $0.58(0.19)$ & $0.64(0.27)$ & 0.32 & $0.72(0.18)$ & $0.69(0.24)$ & 0.69 \\
\hline
\end{tabular}

Quality of life (EQ-5D)

Baseline $\quad 65.05(18.01) \quad 58.72(23.19) \quad 0.21$

73.88 (17.49) $74.93(17.00) \quad 0.81$

3 months $\quad 68.67(20.34) 65.45(23.01) \quad 0.60$

79.22 (13.19) $71.29(15.89) \quad 0.11$

6 months

$64.03(21.73) \quad 67.08(18.24) 0.58$

70.13 (19.13) $74.60(19.02) \quad 0.45$

12 months

$62.55(20.50) 67.00(22.62) \quad 0.46$

Self-efficacy (GSES)

Baseline $\quad 30.55(5.29) \quad 27.93(6.14) \quad 0.06$

3 months $29.51(5.97) \quad 29.64(7.21) \quad 0.94$

6 months $\quad 30.30(4.28) \quad 29.75(7.02) \quad 0.72$

72.94 (19.94) 69.83 (19.78) 0.64

\section{Secondary:}

12 months

$29.81(4.87) \quad 30.40(8.04) \quad 0.75$

$\begin{array}{lll}30.52(3.13) & 30.89(4.52) & 0.73 \\ 31.15(3.16) & 31.25(5.78) & 0.95 \\ 31.31(4.39) & 30.14(6.64) & 0.49 \\ 30.61(7.02) & 31.38(5.24) & 0.69\end{array}$

Depressive symptoms (HADS)

$\begin{array}{lllllll}\text { Baseline } & 6.31(4.20) & 6.40(4.52) & 0.93 & 5.14(3.47) & 5.31(4.27) & 0.86 \\ 3 \text { months } & 6.19(4.44) & 6.88(5.09) & 0.59 & 4.20(2.64) & 6.10(5.35) & 0.16 \\ 6 \text { months } & 6.71(3.85) & 6.40(5.38) & 0.80 & 5.27(3.80) & 5.52(5.25) & 0.85 \\ 12 \text { months } & 6.57(5.07) & 6.72(5.51) & 0.91 & 5.33(3.92) & 5.77(5.01) & 0.76\end{array}$

Anxiety symptoms (HADS)

$\begin{array}{lllllll}\text { Baseline } & 7.33(3.78) & 6.83(4.55) & 0.62 & 6.97(4.14) & 6.86(4.32) & 0.91 \\ 3 \text { months } & 6.64(3.58) & 7.00(4.34) & 0.73 & 6.10(3.38) & 6.90(4.05) & 0.52 \\ 6 \text { months } & 7.35(3.28) & 6.44(5.05) & 0.41 & 6.22(3.82) & 6.47(5.20) & 0.85 \\ 12 \text { months } & 6.53(3.72) & 6.96(5.15) & 0.73 & 6.27(3.35) & 7.54(5.90) & 0.42\end{array}$

Adaptive coping (Brief COPE)

$\begin{array}{lllllll}\text { Baseline } & 2.71(0.64) & 2.56(0.71) & 0.24 & 2.30(0.77) & 2.25(0.68) & 0.80 \\ 3 \text { months } & 2.71(0.64) & 2.47(0.66) & 0.19 & 2.10(0.69) & 1.98(0.77) & 0.62 \\ 6 \text { months } & 2.58(0.79) & 2.39(0.70) & 0.39 & 2.18(0.66) & 1.98(0.75) & 0.35 \\ 12 \text { months } & 2.39(0.71) & 2.38(0.68) & 0.95 & 2.28(0.78) & 2.24(0.80) & 0.87\end{array}$

Maladaptive coping (Brief COPE)

Baseline $\quad 1.86(0.47)$

$1.89(0.54)$

0.85

$1.69(0.46)$

$1.57(0.50) \quad 0.35$

3 months

$2.04(0.69)$

0.37

$1.51(0.38)$

$1.55(0.45) \quad 0.73$

6 months

$1.89(0.41)$

$1.92(0.68)$

0.85

$1.60(0.43)$

$1.68(0.58)$

0.59

12 months $1.94(0.51)$

$1.85(0.66)$

$0.591 .60(0.42)$

$1.72(0.62)$

0.55

Social functioning (WSAS)

Baseline

$18.80(11.46) \quad 19.69(12.83) \quad 0.76$

$14.73(10.44) \quad 15.65(12.32) \quad 0.76$ 


\begin{tabular}{|c|c|c|c|c|c|c|c|}
\hline 905 & 3 months & $20.00(11.14)$ & $17.16(13.41)$ & 0.40 & $15.05(10.97)$ & $17.44(11.96)$ & 0.53 \\
\hline 906 & 6 months & $20.41(11.89)$ & $15.25(12.82)$ & 0.12 & $17.47(10.60)$ & $15.45(11.72)$ & 0.65 \\
\hline 907 & 12 months & $18.85(12.72)$ & $16.12(13.85)$ & 0.46 & $18.31(11.35)$ & $16.38(14.04)$ & 0.63 \\
\hline 908 & \multicolumn{7}{|c|}{ Illness perceptions (BIPQ) } \\
\hline 909 & Baseline & $44.55(12.73)$ & $42.39(15.67)$ & 0.52 & & & \\
\hline 910 & 3 months & $44.84(13.07)$ & $39.04(15.54)$ & 0.13 & & & \\
\hline 911 & 6 months & $45.76(12.82)$ & $39.54(15.21)$ & 0.10 & & & \\
\hline 912 & 12 months & $42.30(15.40)$ & $39.96(16.97)$ & 0.60 & & & \\
\hline 913 & \multicolumn{7}{|c|}{ Carer satisfaction (CASI): person cared for } \\
\hline 914 & Baseline & & & & $2.21(0.78)$ & $2.16(0.66)$ & 0.78 \\
\hline 915 & 3 months & & & & $2.08(0.61)$ & $2.06(0.73)$ & 0.92 \\
\hline 916 & 6 months & & & & $2.30(0.47)$ & $1.74(0.86)$ & $0.01 * *$ \\
\hline 917 & 12 months & & & & $2.30(0.75)$ & $1.92(0.89)$ & 0.16 \\
\hline 918 & \multicolumn{7}{|c|}{ Carer satisfaction (CASI): family carer } \\
\hline 919 & Baseline & & & & $1.54(0.73)$ & $1.50(0.81)$ & 0.85 \\
\hline 920 & 3 months & & & & $1.47(0.51)$ & $1.40(0.67)$ & 0.68 \\
\hline 921 & 6 months & & & & $1.66(0.60)$ & $1.32(0.76)$ & 0.10 \\
\hline 922 & 12 months & & & & $1.62(0.67)$ & $1.46(0.77)$ & 0.48 \\
\hline 923 & \multicolumn{7}{|c|}{ Carer satisfaction (CASI): interpersonal dynamic } \\
\hline 924 & Baseline & & & & $2.06(0.93)$ & $2.03(0.89)$ & 0.88 \\
\hline 925 & 3 months & & & & $1.90(0.86)$ & $1.82(0.84)$ & 0.76 \\
\hline 926 & 6 months & & & & $2.04(0.77)$ & $1.70(0.90)$ & 0.19 \\
\hline 927 & 12 months & & & & $1.98(0.81)$ & $1.72(0.99)$ & 0.38 \\
\hline 928 & \multicolumn{7}{|l|}{ Carer strain (MCSI) } \\
\hline 929 & Baseline & & & & $10.81(5.55)$ & $11.19(6.45)$ & 0.80 \\
\hline 930 & 3 months & & & & $9.78(5.43)$ & $11.52(7.18)$ & 0.41 \\
\hline 931 & 6 months & & & & $11.13(5.67)$ & $9.75(6.46)$ & 0.46 \\
\hline 932 & 12 months & & & & $11.52(5.20)$ & $9.00(6.79)$ & 0.20 \\
\hline 933 & & & & & & & \\
\hline 934 & $e<0.01$ & & & & & & \\
\hline 935 & Independent $t$-test & & & & & & \\
\hline
\end{tabular}

937

938

939

940 


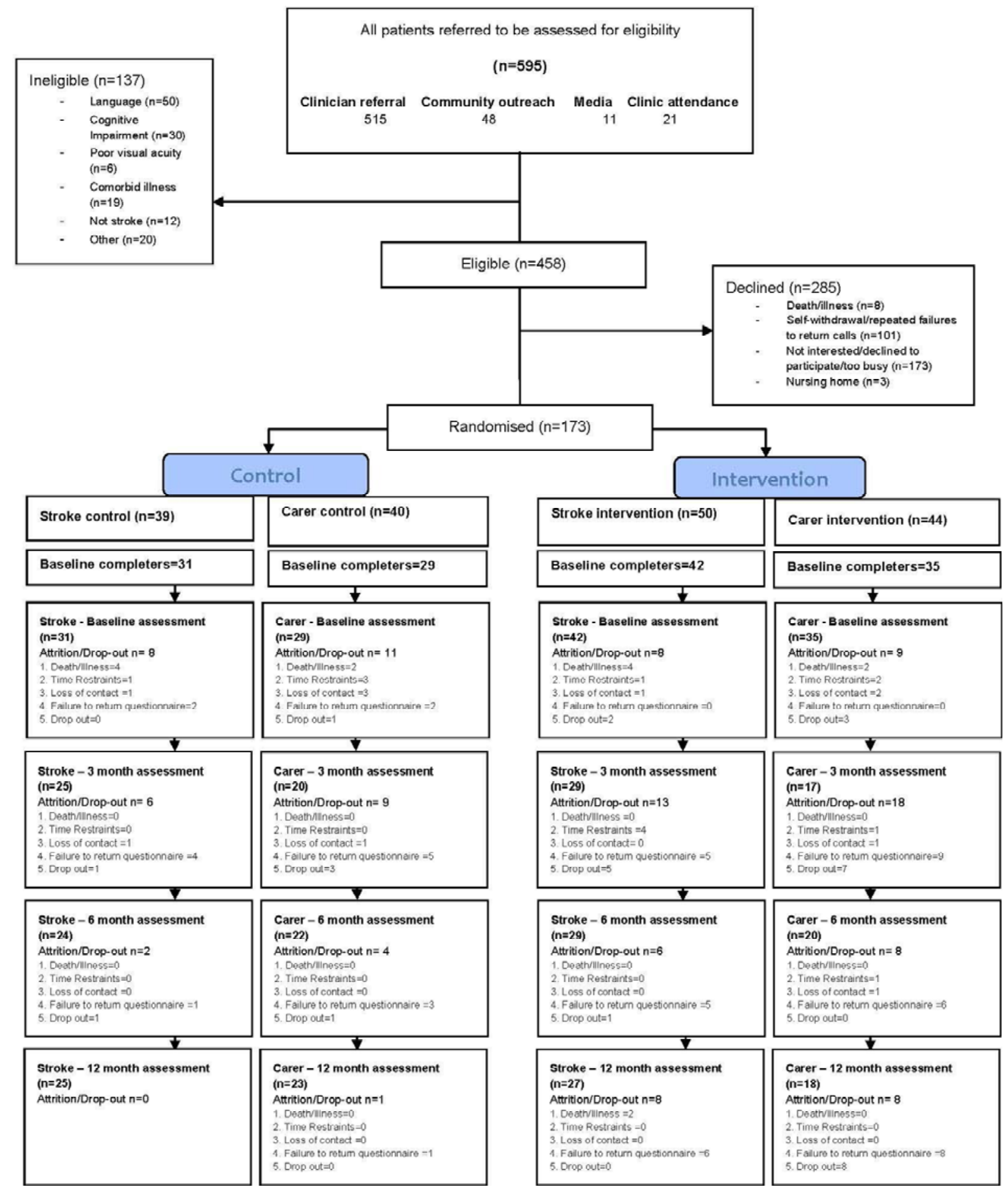

Figure 1. Participant flow chart 